\title{
Activation of whole body by high levels of polyamine intake in rats
}

\author{
Takumi Teratani ${ }^{1,2} \odot$ - Naoya Kasahara ${ }^{2} \cdot$ Tetsuo jichi $^{1} \cdot$ Yasuhiro Fujimoto ${ }^{3} \cdot$ Yasunaru Sakuma $^{2} \cdot$ Naohiro Sata $^{2}$. \\ Joji Kitayama ${ }^{1,2}$
}

Received: 13 July 2021 / Accepted: 17 September 2021 / Published online: 15 October 2021

(c) The Author(s) 2021

\begin{abstract}
Polyamines are important to the survival and activation of organs and tissues via a homeostatic cell-metabolic process, and the polyamine content in cytoplasm decreases with aging. Decreases in cellular polyamine have been known to augment mutagenesis and cell death. Thus, supplementary polyamine in food is important to the prevention of aging. Here we show the anti-aging effects of oral intake of polyamine using luciferase-transgenic rats. Healthy rats, $10-12$ weeks old, were given foods containing $0.01 \%$ and $0.1 \%(\mathrm{w} / \mathrm{w}$ ) of polyamine, as compared a control food without polyamine, for 4 weeks. Using a bioimaging system, the photon intensities seen in the whole bodies and livers of rats consuming $0.1 \%$ of polyamine in food were stronger than those in rats consuming $0.01 \%$ and $0 \%$ of polyamine. However, there were no differences between groups in other characteristics, such as liver damage and body weight. In conclusion, we found that polyamine intake can activate cells throughout the whole body, providing an anti-aging effect.
\end{abstract}

Keywords Polyamine $\cdot$ Oral intake $\cdot$ Anti-aging $\cdot$ Transgenic rat $\cdot$ Living imaging

\section{Introduction}

Polyamines are polycationic biogenic amines required for both eukaryotic cell growth and differentiation. They have attracted interest because of their multiple functions in cell biology (Mattoo et al. 2010; Tavladoraki et al. 2011), and studies have indicated that extracellular sources of polyamines are also important in metabolic processes (Rigueira et al. 2011). Polyamine synthesis decreases with aging, and a growing child produces the highest amounts of polyamine. Initially, polyamine is consumed in mother's milk in early childhood. At least in animal models, the polyamine content in the mother's milk, in combination with the immature de novo polyamine synthesis capacity in neonatal cells,

Handling editor: S. Beninati.

Takumi Teratani

teratani@jichi.ac.jp

1 Division of Translational Research, Jichi Medical University, 3311-1, Yakushiji, Shimotsukeshi, Tochigi 329-0498, Japan

2 Department of Surgery, Jichi Medical University, 3311-1, Yakushiji, Shimotsukeshi, Tochigi 329-0498, Japan

3 Department of Surgery, Hyogo College of Medicine, 1-3-6 Minatojima, Chuo-ku, Kobeshi, Hyogo 663-8501, Japan influences the maturation and function of the neonatal intestinal mucosa and probably aids various immunological functions (Duchén and Thorell 1999). The polyamine (putrescine, spermine, and spermidine) concentrations in mother's milk and infant formulas were estimated by high-pressure liquid chromatography (HPLC; Romain et al. 1992). However, polyamines are naturally present at low concentrations in living organisms and in foods; thereby, the amount synthesized in situ may not be enough to meet health maintenance requirements. Therefore, supplementing polyamine is necessary for sufficient metabolic synthesis.

Meanwhile, aging is defined as a universal, progressive, and deleterious process occurring in cells and tissues, affecting most the living organisms. It is usually associated with progressive loss in functions across multiple systems, including sensation, cognition, memory, and motor control. Cognitive decline is a universal aspect of the aging process (Singh et al. 2011). In the aging process, as well as in most degenerative diseases, oxidant byproducts of the cellular metabolism lead to oxidative stress (Bianchi et al. 2007). Oxidative stress damages DNA in the host genome and induces apoptosis (Okita et al. 2007; Saeki et al. 2011). Since they are positively charged, spermine and spermidine interact with and stabilize DNA and RNA. Inhibition of these interactions between polyamine and DNA and/or low 
levels of spermine have been found to cause radio sensitivity, augmented mutagenesis, and cell death (Beckman and Ames 1997; Bianchi et al. 2007). Thus, as the amount of polyamine in the body increases, DNA and/or RNA damage is suppressed, which may greatly contribute to anti-aging effects.

Visualizing the state of cells across the whole body is very useful. Adenosine tri-phosphate (ATP) is an essential energy factor for living cells and vital activity, and is used in DNA and RNA synthesis. Like polyamine's, ATP's synthesizing activity decreases with aging (Haynes et al. 2010). We previously described the use of a luciferase transgenic (Luc$\mathrm{Tg}$ ) rat system, together with optical imaging techniques, to better understand cell and/or tissue conditions (Hakamata et al. 2006; Teratani and Kobayashi 2012). We previously described the use of a luciferase-based cell-viability assay that detects intracellular ATP levels in viable cells, which we used to assess the viability of Luc-Tg rat-derived islets and kidney, heart, small intestine, and liver samples (Doi et al. 2014; Iwai et al. 2012, 2014; Kasahara et al. 2013; Maeda et al. 2013; Negishi et al. 2011; Teratani and Kobayashi 2012).

In this study, we examined whether the long-term intake of polyamine-containing foods can increase whole body photon intensity levels in Luc-Tg rats. Additionally, we evaluated the safety of oral ingestion of polyamine at different concentrations, by examining major liver and kidney injury markers.

\section{Materials and methods}

\section{Experimental animals}

All experiments in this study were performed in accordance with protocols of the Jichi Medical School Guide for Laboratory Animals. The firefly Luciferase-expression transgenic Lewis rat (Luc-Tg LEW rat) was established in our laboratory as described previously (Hakamata et al. 2006; Teratani and Kobayashi 2011). Male Luc-Tg LEW rats weighing between 260 and $310 \mathrm{~g}, 10$ and 12 weeks old, were used for the experiment. The animals were housed in a temperatureand humidity-controlled environment with a 12-h light/dark cycle and were provided with standard laboratory chow and water ad libitum.

\section{Polyamine-containing food}

Test foods for the animal experiments were prepared by eliminating polyamine-rich materials from a standard rodent diet (0\%; Oriental BIO Co., Ibaraki, Japan). For the test food with a high polyamine concentration $(0.1 \%)$, synthetic spermine and spermidine (Wako Pure Chemical Industries, Ltd., Osaka, Japan) were mixed in doses of $80 \mu \mathrm{mol} / \mathrm{kg}$ and 360 $\mu \mathrm{mol} / \mathrm{kg}$, respectively, into the test food with a non-polyamine concentration. For the test food with a low polyamine concentration $(0.01 \%)$, spermine and spermidine were mixed in doses of $8 \mu \mathrm{mol} / \mathrm{kg}$ and $36 \mu \mathrm{mol} / \mathrm{kg}$, respectively, into the test food with a non-polyamine concentration. The test foods were prepared as pellets.

\section{In vivo bioluminescence imaging}

In vivo luciferase imaging was performed using the in vivo imagining system (IVIS) and the IVIS Living Image software (Xenogen, Alameda, CA, USA). To detect photons from Luc-Tg rats' whole bodies and tissues, D-luciferin (Promega, Madison, WI, USA) was injected into the tail veins of anesthetized rats $(150 \mathrm{mg} / \mathrm{kg}$; Negishi et al. 2011). Signal intensity was quantified as photon flux in units of photons $/ \mathrm{s} / \mathrm{cm}^{2} / \mathrm{steradian}$ in the region of interest.

\section{Measurement of polyamines}

Amino acids were removed by cellulose phosphate column chromatography before the polyamine analysis because the polyamine levels in plasma were very low. We added $0.2 \mathrm{ml}$ of $50 \%$ trichloroacetic acid to $1.8 \mathrm{ml}$ plasma and centrifuged it for $10 \mathrm{~min}$ at $12,000 \mathrm{~g}$. The supernatant thus obtained was neutralized with $6 \mathrm{~N} \mathrm{KOH}$ and applied to a cellulose phosphate column $(1 \mathrm{ml})$ previously equilibrated with a buffer containing $0.1 \mathrm{M}$ boric acid-Na2CO3 and $0.025 \mathrm{M}$ $\mathrm{NaCl}(\mathrm{pH}$ 8.0). Amino acids were eluted with $10 \mathrm{ml}$ of the same buffer and polyamines were then eluted with $3 \mathrm{ml}$ of a buffer containing $0.2 \mathrm{M}$ boric acid-Na2CO3 and $0.8 \mathrm{M}$ $\mathrm{NaCl}$ ( $\mathrm{pH}$ 8.0). The polyamine content was measured by HPLC as described previously (Igarashi et al. 1986; Sakata et al. 2003).

\section{Assessment of liver functions}

Blood samples were obtained from each rat and centrifuged for $10 \mathrm{~min}$ at $3000 \mathrm{rpm}$, and serum was collected. Concentrations of markers of liver injury were analyzed using a FUJIFILM DRI-CHEM 3500 machine (FujiFilm, Tokyo, Japan) and FUJI DRY CHEM SLIDES (FujiFilm), respectively, for GOT/aspartate aminotransferase-PIII and GPT/ alanine transaminase-PIII.

\section{Immunohistochemistry}

An immunohistochemical study was performed on $10 \%$ formalin-fixed, paraffin-embedded tissues derived from each resected rat liver. Serial sections from each representative tissue block were deparaffinized and dehydrated. Tissue sections were then incubated with a primary monoclonal antibody against Ki67 (clone MIB-1, dilution 1:250; Dako, 
Tokyo, Japan), and incubated for $24 \mathrm{~h}$ in a cold room. The rhodamine- (dilution 1:1000) or FITC- (dilution 1:1000) conjugated secondary antibodies were applied for $30 \mathrm{~min}$ at room temperature. Eight-micron paraffine-embedded sections were stained with hematoxylin and eosin for conventional morphological evaluation. Paraffin sections of the post-operation days 7 (POD7) rat livers were prepared.

\section{Statistical analysis}

Data are presented as means \pm standard deviations. The statistical analysis was conducted using a Student's $t$-test and a non-repeated measurement analysis of variance, followed by a Bonferroni post hoc comparison test. We considered $P$ values $<0.05$ to indicate statistical significance.

\section{Results}

\section{Polyamine-containing foods}

We tested 3 different polyamine-containing foods. Neither the amounts of food consumed (Fig. 1a) nor the body weights (Fig. 1b) differed between groups. Thus, these results suggest that polyamine supplementation does not induce asitia and/or growth failure in rats. In this experiment, we used these foods to test the anti-aging effects of polyamine in Luc-Tg rats.

\section{Effects of polyamine-containing foods on photon intensity}

The new field of in vivo imaging is being developed with luminescent biotechnology, and involves the real-time visualization of complex cellular processes in living animals. In inbred $\mathrm{Tg}$ rats with firefly luciferase, we compared levels of photon intensity between a young Luc-Tg rat (6 weeks old) and an older Luc-Tg rat (28 weeks old) using an in vivo imaging system (Online Resource 1). The photon intensity across the whole body was stronger in the young Luc-Tg rat than in the older Luc-Tg rat. Additionally, the photon intensity levels of organs and tissues decreased with age (data not shown).

Next, we investigated the anti-aging effects of test foods supplemented with polyamine in Luc-Tg rats. The photon intensity levels increased with higher concentrations of polyamine, and did not change in the group without supplementation (Fig. 2a). Furthermore, time-dependent changes in photon intensity levels were quantified from images taken with the IVIS Living Image software (Fig. 2b). When comparing intensity levels after 4 weeks, the photon intensity had increased by 1.2 -fold in the group consuming $0.01 \%$ of polyamine in food $(118.607 \pm 17.911 \%)$ and by 1.6 -fold in the

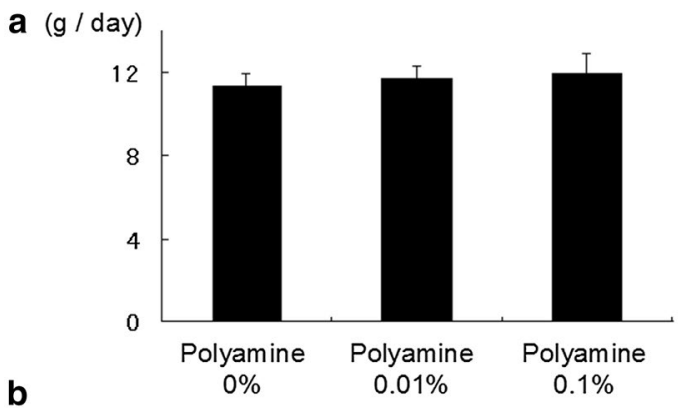

(g/body)

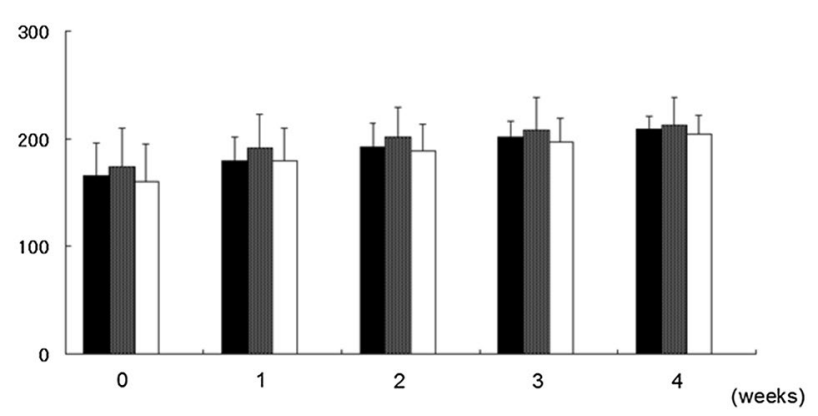

Fig. 1 Analysis of the conditions of rats consuming the test foods ( $n=6$ each). a Daily intake of 10 -week-old Luc-Tg rats. There was no change in intake amounts due to changes in polyamine content. b Furthermore, there was no weight change. The black bar indicates $0 \%$ of polyamine in food, the gray bar indicates $0.01 \%$ of polyamine, and the white bar indicates $0.1 \%$ of polyamine

group consuming $0.1 \%$ of polyamine $(159.543 \pm 19.897 \%)$, compared with the group consuming $0 \%$ of polyamine $(94.505 \pm 12.579 \%)$. Thus, these results suggest systemically anti-aging effects of polyamine consumption in rats. Additionally, the anti-aging effect was found to change in proportion to the polyamine concentration.

\section{Effects of polyamine on activation of the liver}

We analyzed the impacts of polyamine intake for 4 weeks on the livers of Luc-Tg rats using IVIS (Fig. 3a). The photon intensity level increased with consumption of polyamine, similar to results from our analysis of the whole body. Next, the photon intensity levels in liver were quantified from these IVIS image files based on the test foods (Fig. 3b). The photon intensity level increases in the liver were proportional to the polyamine concentration increases, with the same levels in rats consuming $0.1 \%$ of polyamine and in young rats at 6 weeks of age (Online Resource 2). We investigated the accumulation of polyamines in rat livers by HPLC analysis (Fig. 3c). Rats consuming 0\% and $0.01 \%$ of polyamine had significant differences in liver polyamine concentrations; however, those consuming $0.1 \%$ of polyamine had a significant difference. Thus, these results suggest 
Fig. 2 Changes in photon intensity based on intake of polyamine ( $n=6$ each). a Kinetics of photon intensity levels over several weeks. b The value of the photon intensity at the 0 th week was set to $100 \%$. c In the bar graph, each groups' values are shown at $0,1,2,3$, and 4 weeks from left to right. The food with $0.01 \%$ polyamine has the same polyamine content as normal commercial foods

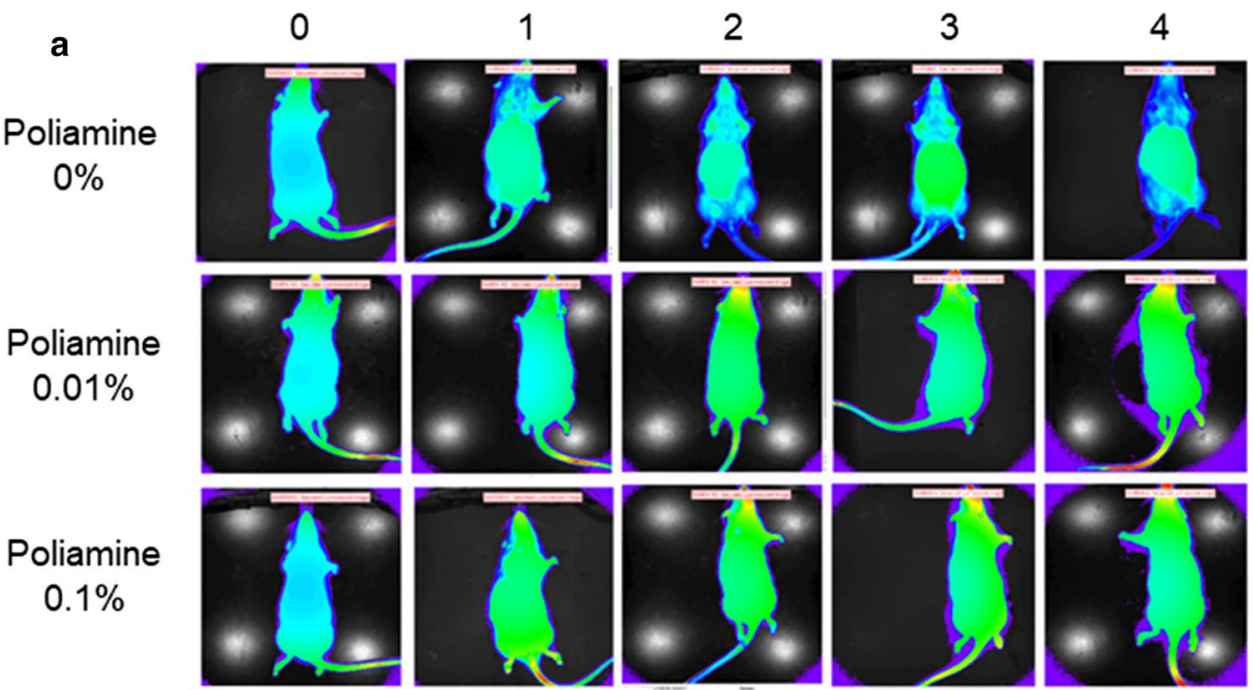

b $(\%)$

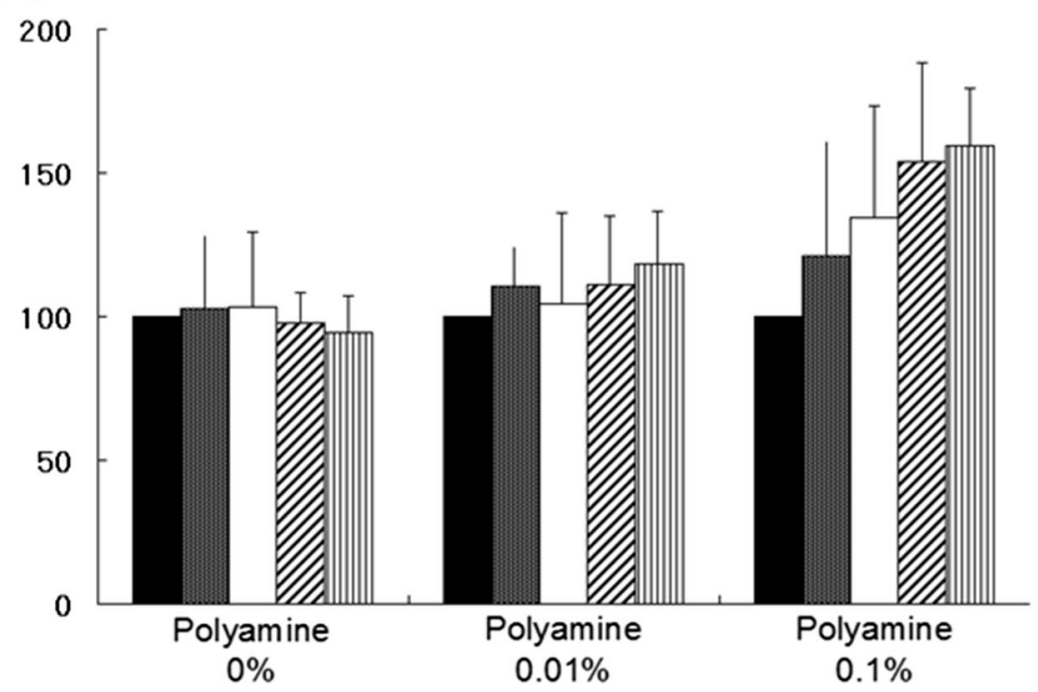

that polyamine has a direct effect on anti-aging and/or cell viability of several organs.

\section{Analysis of liver toxicity by test food group}

Finally, we investigated the polyamine toxicity within groups by testing liver sections and serum in rats. Biochemical parameters such as GOT and GPT were not increased in mice consuming polyamine-containing foods, compared to those consuming food without polyamine (Fig. 4a). Furthermore, there were no pathological differences in liver sections between groups (Fig. 4b). However, Ki67-positive cells of cell proliferation maker were increased in rats consuming polyamine-containing test foods $(0.01 \%$ and $0.1 \%$ polyamine), compared with controls (Fig. 4c). However, TdTmediated dUTP nickend labeling (TUNEL)-positive cells of an apoptosis marker were not found to significantly differ across groups (data not shown). Thus, 4 weeks of consuming $0.1 \%$ of polyamine does not lead to toxicity. Furthermore, the function of polyamine was clear based on the inhibition of apoptosis and on liver proliferation.

\section{Discussion}

The polyamines spermine, spermidine, and putrescine are ubiquitous cell components that are essential for cell proliferation and differentiation (Pegg 1988). They attract interest because of their multiple functions in cell biology, including cell cycle regulation, gene expression, and signal transduction, among many others (Agostinelli et al. 2010; Bachrach et al. 2001; Childs et al. 2003). Polyamine levels decrease with age in many organisms (Scalabrino and Ferioli 1984), although decreases are polyamine and tissue specific. For 
Fig. 3 Photon images of rat livers based on polyamine intake $(n=6$. each). a After 4 weeks of oral intake, the rats' whole livers were removed using by IVIS. b Photon intensity values are shown for rats consuming $0 \%, 0.01 \%$, and $0.1 \%$ of polyamine in food. Photon levels of rats consuming foods with $0 \%$ and $0.01 \%$ of polyamine were significantly lower than those of rats consuming $0.1 \%$ of polyamine in food $(P<0.01)$. $\mathbf{c}$ The polyamine concentrations of rat livers were examined in each experimental group using high-pressure liquid chromatography. The black bar indicates $0 \%$ of polyamine in food, the gray bar indicates $0.01 \%$ of polyamine, and the white bar indicates $0.1 \%$ of polyamine $(P<0.01)$

instance, Nishimura et al. (2006) measured polyamine levels in 14 different tissues in 3-, 10-, and 26-week-old female mice and found that spermidine levels decreased in 11 out of the 14 tissues. In contrast, spermine decreased only in the skin, heart, and muscles. Putrescine levels were very low in all tissues at all ages. Eisenberg et al. (2009) followed the consequences of external spermidine administration in various model organisms, including yeast, worms, flies, mice, and human cells (Eisenberg et al. 2009; Minois et al. 2011). Spermidine increased the chronological life span in wildtype yeast, as well as the remaining replicative life span in old yeast cells. In contrast, a $\Delta$ spe 1 yeast mutant unable to synthesize polyamines was short-lived. This decreased life span was rescued by the addition of spermidine, as well as of putrescine. Additionally, spermidine supplementation increased the life span of the nematode worm Caenorhabditis elegans by $15 \%$ and of the fly Drosophila melanogaster by up to $30 \%$. At the cellular level, spermidine increased survival of human peripheral blood mononuclear cells after 2 days from $15 \%$ in controls to $50 \%$ by preventing death from necrosis.

The main source of exogenous polyamines is dietary (Larqué et al. 2007), and the intestinal lumen is the main exogenous source for the body (Hosomi et al. 1987; Osborne and Seidel 1990). Since the level of polyamines decreases with age in animal organs (brain, kidney, spleen, and pancreas), it has been suggested that maintenance of the polyamine level from the diet is important to the functioning of various organs in the elderly (Das and Kanungo 1982; Larqué et al. 2007). A high intake of spermine is associated with a decreased risk of food allergies among suckling rats, as well as human children, due to the contribution of spermine to maturation of both the immune system and the small intestinal mucosa (Ali et al. 2011; Dandrifosse et al. 2000; Dufour et al. 1988; Löser 2000).

At the same time, aging is a fundamental biological phenomenon of great medical importance (Anand et al. 2012). It is well known that many age-related behavioral changes occur even in the absence of specific, age-related, neurodegenerative diseases, such as Alzheimer's disease or Parkinson's disease (Butterfield et al. 1999). D-galactose causes age-related changes in different animal models. It has been a

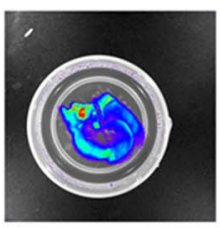

$0 \%$

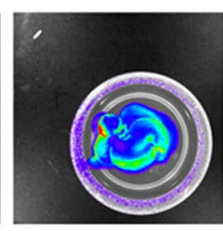

$0.01 \%$

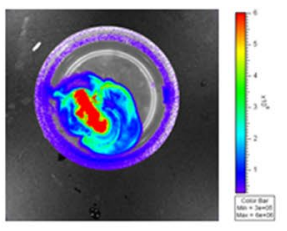

$0.1 \%$
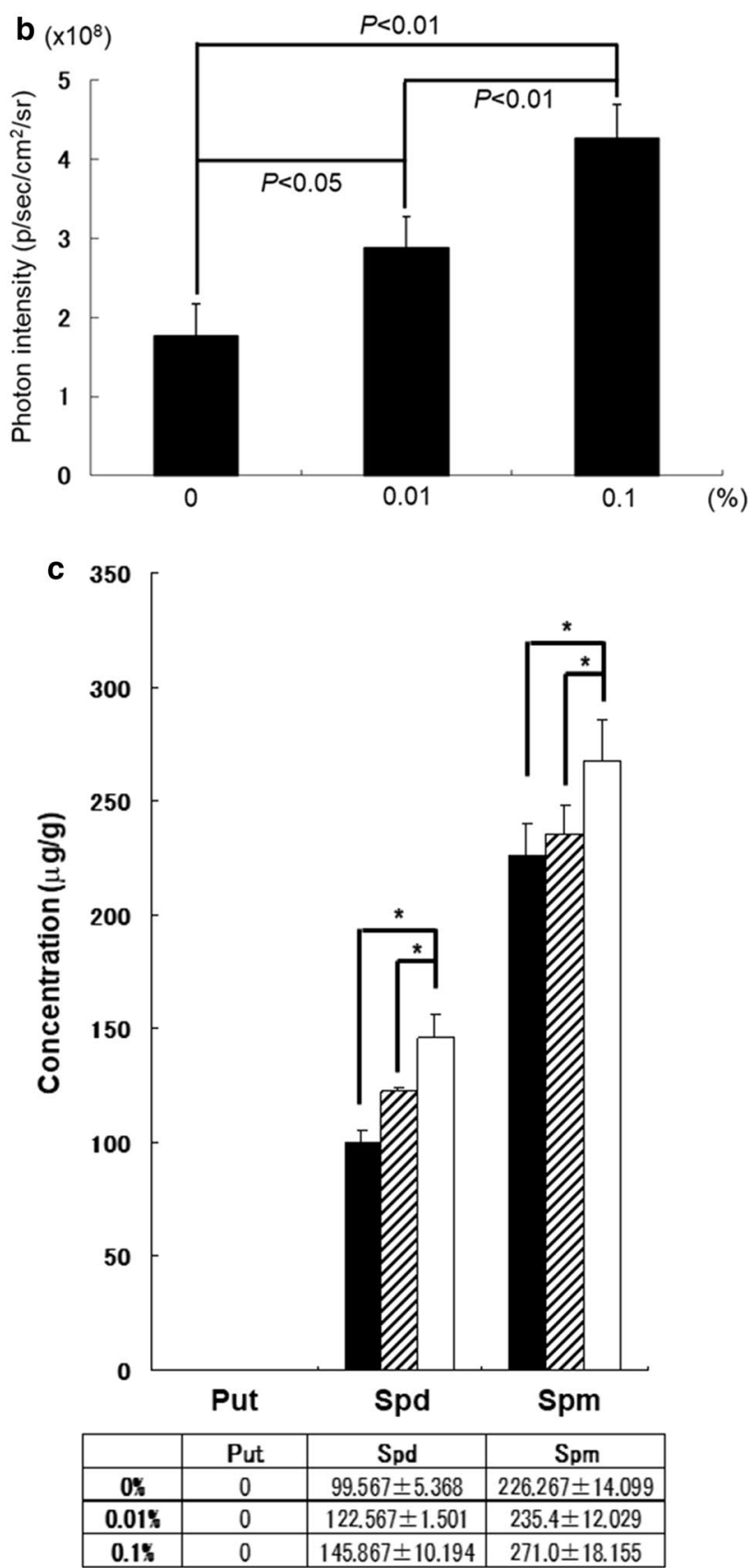

reported that free radicals are increased in animals receiving D-galactose, and the free radical theory of aging shows that these increased free radicals might contribute to the mechanisms underlying age-related degenerative diseases (Ho et al. 2003). Oxidative stress is the result of an imbalance between 
Fig. 4 Analysis of serum and pathological specimens. a Serum levels of aspartate aminotransferase and alanine transaminase are shown at 0-4 weeks of oral intake of foods with polyamine $(n=6$ each). The black bar indicates $0 \%$ of polyamine in food, the gray bar indicates $0.01 \%$ of polyamine, and the white bar indicates $0.1 \%$ of polyamine. Representative b hematoxylin and eosin-stained and $\mathbf{c}$ $\mathrm{Ki}$-67-stained sections of liver. Arrows indicate Ki-67-positive cells of hepatocytes. Original magnification $\times 100$. Scale bars, $200 \mu \mathrm{m}$
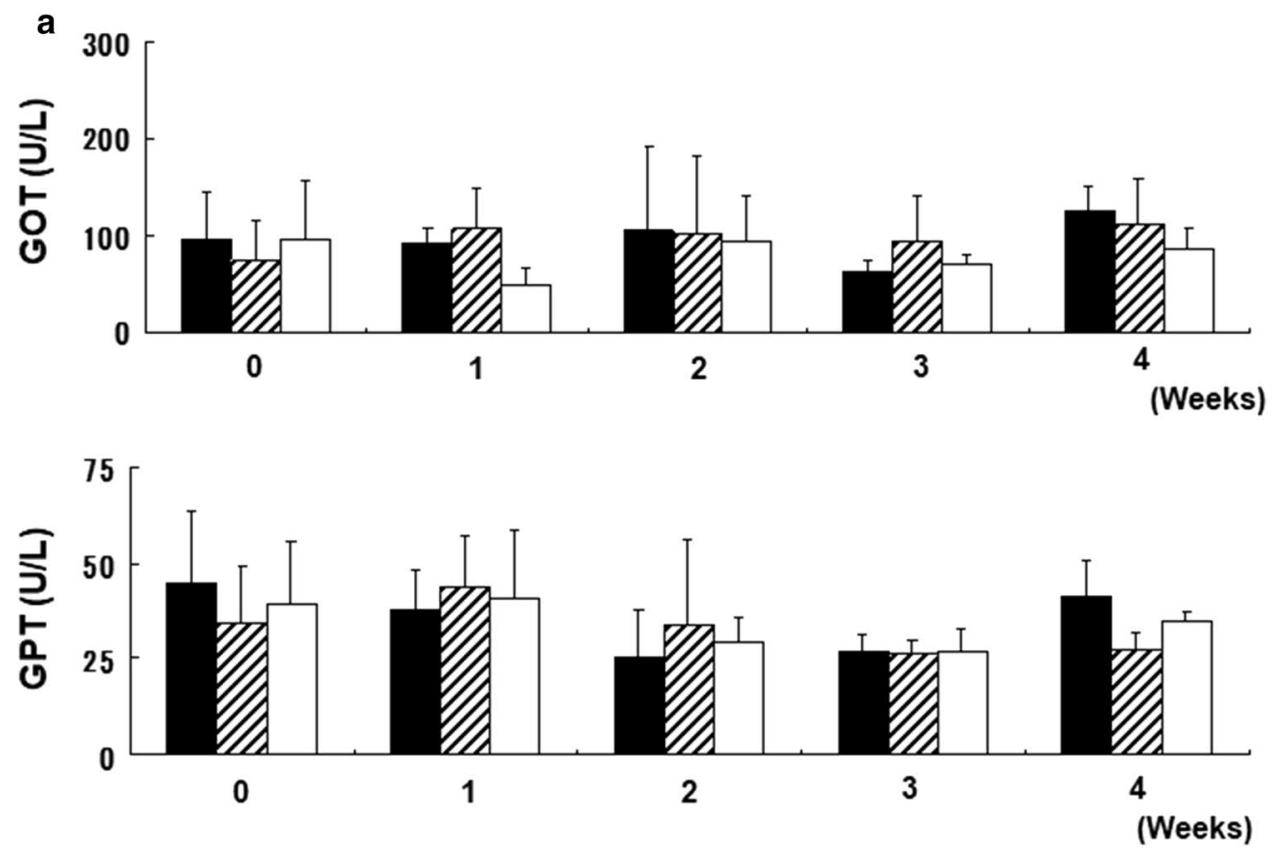

b

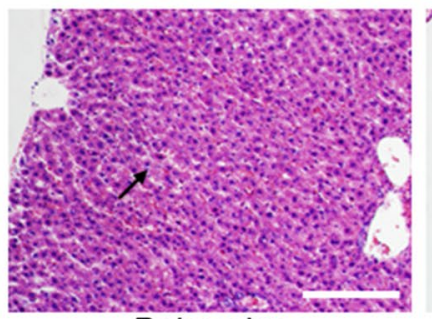

Polyamine

$0 \%$

c

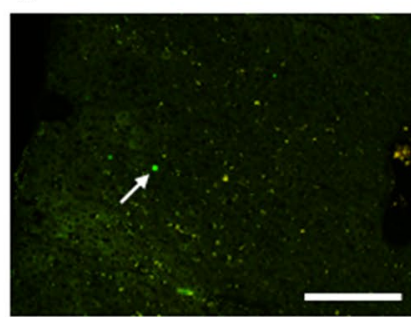

Polyamine

$0 \%$

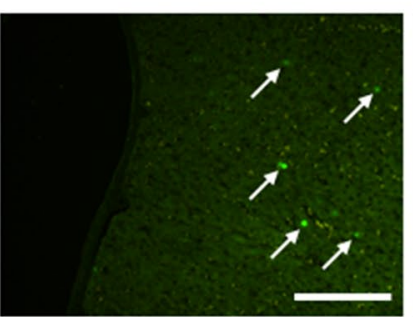

Polyamine

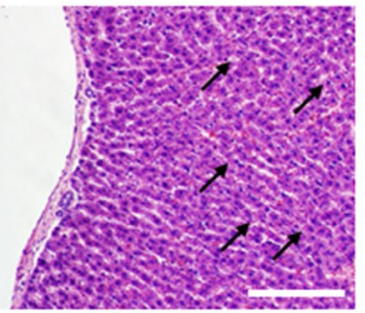

Polyamine

$0.01 \%$

$0.01 \%$

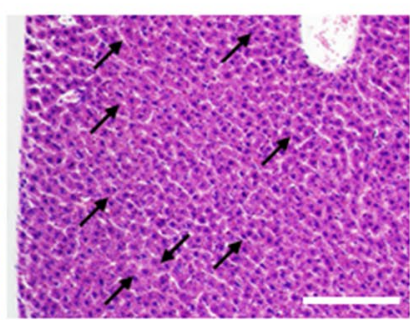

Polyamine

$0.1 \%$

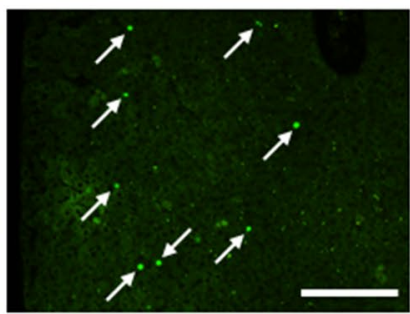

Polyamine

$0.1 \%$ generation and scavenging of reactive oxygen species (ROS). Old cells have higher levels of ROS than young cells (Hagen et al. 1997; Lee et al. 1999). Senescent states of cells can be readily induced by sub-lethal doses of pro-oxidants (Chen and Ames 1994; Chen et al. 1998). Thus, any adjustment to the ROS balance is expected to prevent or restore cellular senescence (Kim and Wu 2009; Kim and Park 2012). Endogenous free radical scavengers such as polyamines can inhibit the action of ROS. Furthermore, polyamines have been shown to indirectly increase HO- 1 content and antioxidant protection (von Deutsch et al. 2005). Furthermore,
ATP synthesis ability decreases in major organs such as the liver and brain with aging (Alemany et al 1988; Eckert et al. 2013). The reason is that the quality of mitochondria deteriorates due to aging, and the increase in oxidative stress reduces the amount of ATP produced (Rodríguez et al. 2008).

Recently, we found that perioperative oral polyamine administration attenuates liver ischemia-reperfusion injury and promotes liver regeneration (Doi et al. 2019; Okumura et al. 2016). In a liver ischemia-reperfusion injury, the number of PCNA (Proliferation cell nuclear antigen)-positive 
and Ki67-positive cells were increased in the polyamine group compared to the non-polyamine group. Okumura et al.'s (2016) report suggests that postoperative cell proliferation, DNA synthesis, and liver regeneration were promoted by polyamine treatment. HE staining indicates that there is no abnormality in the liver pathologically, and at the same time, which cells are Ki67-positive. It has also been found that the Ki67-positive rate decreases with aging (Kalaz et al. 2014). This figure shows that oral intake of polyamines in aged rats restores Ki67-positive cells to the same level as in young rats. Furthermore, in a study investigating the effects of polyamines, our team found that oral polyamines have a wide range of therapeutic effects in vitro and in vivo, including promotion of anti-aging, testicular activation, cartilage regeneration, and short bowel syndrome (Preparation of manuscripts). Especially, based on short bowel syndrome's basic research data, we took the lead in conducting a clinical trial of oral polyamines in a patient with short bowel syndrome after obtaining approval from the Ethics Committee in the Jichi Medical University Hospital (Approval No. 16-47). As a result, a significant improvement in quality of life was confirmed, including an improvement in nutritional status and a significant decrease in the frequency of diarrhea. Furthermore, oral polyamine had no adverse effects on other medical conditions (Preparation of manuscript).

In conclusion, using an in vivo imaging system we found here that intake of polyamine activates cells in the whole body and provides an anti-aging effect.

Supplementary Information The online version contains supplementary material available at https://doi.org/10.1007/s00726-021-03079-4.

Acknowledgements We wish to thank all personnel in the Division of Translational Research, Jichi Medical University. The authors are grateful to Prof. Dr. Eiji Kobayashi in Department of Organ Fabrication, Keio University School of Medicine, and Takumi Watanabe and Ayako Sakano as Combi Corp. technical-staff for kindly providing and analysis of polyamine samples.

Author contributions TT: participated in the research design; NS and TT: wrote the manuscript; NK, TI and TT: performed the research; and NK, YF, NS, JK and TT: analyzed the data.

Funding The authors have no support or funding to report.

Availability of data and material Only if you make a prior notice to the corresponding author, all of the data is fully available without restriction

Code availability Not applicable.

\section{Declarations}

Conflicts of interest/Competing interests Author T. Ijichi has been a visiting Collaborative Researcher at Jichi Medical University and a Chief Manager of R\&D Group to Division of Functional Foods, Com- bi Corporation. (Saitama, Japan) from 2010. In this research result was patented (No. 5909173 and No. 6117963).

Ethics approval This article does not contain any studies with human participants. All procedures involving animals were approved by the ethical committee of Center for Experimental Medicine, Jichi Medical University, Tochigi, Japan.

Consent to participate Not applicable.

Consent for publication Not applicable.

Open Access This article is licensed under a Creative Commons Attribution 4.0 International License, which permits use, sharing, adaptation, distribution and reproduction in any medium or format, as long as you give appropriate credit to the original author(s) and the source, provide a link to the Creative Commons licence, and indicate if changes were made. The images or other third party material in this article are included in the article's Creative Commons licence, unless indicated otherwise in a credit line to the material. If material is not included in the article's Creative Commons licence and your intended use is not permitted by statutory regulation or exceeds the permitted use, you will need to obtain permission directly from the copyright holder. To view a copy of this licence, visit http://creativecommons.org/licenses/by/4.0/.

\section{References}

Agostinelli E, Tempera G, Viceconte N, Saccoccio S, Battaglia V, Grancara S, Toninello A, Stevanato R (2010) Potential anticancer application of polyamine oxidation products formed by amine oxidase: a new therapeutic approach. Amino Acids 38:353-368

Alemany J, de la Cruz MJ, Roncero I, Miquel J (1988) Effects of aging on respiration, ATP levels and calcium transport in rat liver mitochondria. Response to theophylline. Exp Gerontol 23:25-34

Ali MA, Poortvliet E, Strömberg R, Yngve A (2011) Polyamines: total daily intake in adolescents compared to the intake estimated from the Swedish Nutrition Recommendations Objectified (SNO). Food Nutr Res 55:5455

Anand KV, Mohamed Jaabir MS, Thomas PA, Geraldine P (2012) Protective role of chrysin against oxidative stress in d-galactoseinduced aging in an experimental rat model. Geriatr Gerontol Int 12:741-750

Bachrach U, Ash I, Abu-Elheiga L, Hershkovitz M, Loyter A (1987) Fusion-mediated microinjection of active amine and diamine oxidases into cultured cells: effect on protein and DNA synthesis in chick embryo fibroblasts and in glioma cells. J Cell Physiol 131:92-98

Bachrach U, Wang YC, Tabib A (2001) Polyamines: new cues in cellular signal transduction. News Physiol Sci 16:106-109

Beckman KB, Ames BN (1997) Oxidative decay of DNA. J Biol Chem 272:19633-19636

Bianchi M, Bellini A, Cervelli M, Degan P, Marcocci L, Martini F, Scatteia M, Mariottini P, Amendola R (2007) Chronic sub-lethal oxidative stress by spermine oxidase overactivity induces continuous DNA repair and hypersensitivity to radiation exposure. Biochim Biophys Acta 1773:774-783

Butterfield DA, Howard B, Yatin S, Koppal T, Drake J, Hensley K, Aksenov M, Aksenova M, Subramaniam R, Varadarajan S, HarrisWhite ME, Pedigo NW Jr, Carney JM (1999) Elevated oxidative stress in models of normal brain aging and Alzheimer's disease. Life Sci 65:1883-1892 
Chen Q, Ames BN (1994) Senescence-like growth arrest induced by hydrogen peroxide in human diploid fibroblast F65 cells. Proc Natl Acad Sci USA 91:4130-4134

Chen QM, Bartholomew JC, Campisi J, Acosta M, Reagan JD, Ames BN (1998) Molecular analysis of H2O2-induced senescent-like growth arrest in normal human fibroblasts: $\mathrm{p} 53$ and $\mathrm{Rb}$ control G1 arrest but not cell replication. Biochem J 332:43-50

Childs AC, Mehta DJ, Gerner EW (2003) Polyamine-dependent gene expression. Cell Mol Life Sci 60:1394-1406

Dandrifosse G, Peulen O, El Khefif N, El Khefif N, Deloyer P, Dandrifosse AC, Grandfils C (2000) Are milk polyamines preventive agents against food allergy? Proc Nutr Soc 59:81-86

Das R, Kanungo MS (1982) Activity and modulation of ornithine decarboxylase and concentrations of polyamines in various tissues of rats as a function of age. Exp Gerontol 17:95-103

Doi J, Kasahara N, Kikuchi T, Fujimoto Y, Teratani T, Uemoto S, Kobayashi E (2014) Evaluation of liver preservation solutions by using rats transgenic for luciferase. Transplant Proc 46:63-65

Doi J, Fujimoto Y, Teratani T, Kasahara N, Maeda M, Tsuruyama T, Iida T, Yagi S, Uemoto S (2019) Bolus administration of polyamines boosts effects on hepaticischemia-reperfusion injury and regeneration in rats. Eur Surg Res 60:63-73

Duchén K, Thorell L (1999) Nucleotide and polyamine levels in colostrum and mature milk in relation to maternal atopy and atopic development in the children. Acta Paediatr 88:1338-1343

Dufour C, Dandrifosse G, Forget P, Vermesse F, Romain N, Lepoint P (1988) Spermine and spermidine induce intestinal maturation in the rat. Gastroenterology 95:112-116

Eckert GP, Schiborr C, Hagl S, Abdel-Kader R, Müller WE, Rimbach G, Frank J (2013) Curcumin prevents mitochondrial dysfunction in the brain of the senescence-accelerated mouse-prone 8 . Neurochem Int 62:595-602

Eisenberg T, Knauer H, Schauer A, Büttner S, Ruckenstuhl C, Carmona-Gutierrez D, Ring J, Schroeder S, Magnes C, Antonacci L, Fussi H, Deszcz L, Hartl R, Schraml E, Criollo A, Megalou E, Weiskop D, Laun P, Heeren G, Breitenbach M, Grubeck-Loebenstein B, Herker E, Fahrenkrog B, Fröhlic KU, Sinner F, Tavernarakis N, Minois N, Kroemer G, Madeo F (2009) Induction of autophagy by spermidine promotes longevity. Nat Cell Biol 11:1305-1314

Hagen TM, Yowe DL, Bartholomew JC, Wehr CM, Do KL, Park JY, Ames BN (1997) Mitochondrial decay in hepatocytes from old rats: membrane potential declines, heterogeneity and oxidants increase. Proc Natl Acad Sci USA 94:3064-3069

Hakamata Y, Murakami T, Kobayashi E (2006) "Firefly rats" as an organ/cellular source for long-term in vivo bioluminescent imaging. Transplantation 81:1179-1184

Haynes V, Traaseth NJ, Elfering S, Fujisawa Y, Giulivi C (2010) Nitration of specific tyrosines in FoF1 ATP synthase and activity loss in aging. J Physiol Endocrinol Metab 298:E978-E987

Ho SC, Liu JH, Wu RY (2003) Establishment of the mimetic aging effect in mice caused by D galactose. Biogerontology 4:15-18

Hosomi M, Lirussi F, Stace NH, Vaja S, Murphy GM, Dowling RH (1987) Mucosal polyamine profile in normal and adapting (hypo and hyperplastic) intestine: effects of DFMO treatment. Gut 28:103-107

Igarashi K, Kashiwagi K, Hamasaki H, Miura A, Kakegawa T, Hirose S, Matsuzaki S (1986) Formation of a compensatory polyamine by Escherichia coli polyamine-requiring mutants during growth in the absence of polyamines. J Bacteriol 166:128-134

Iwai S, Kikuchi T, Kasahara N, Teratani T, Yokoo T, Sakonju I, Okano S, Kobayashi E (2012) Impact of normothermic preservation with extracellular type solution containing trehalose on rat kidney grafting from a cardiac death donor. PLoS ONE 7:e33157

Iwai S, Sakonju I, Okano S, Teratani T, Kasahara N, Yokote S, Yokoo T, Kobayash E (2014) Impact of ex vivo administration of mesenchymal stem cells on the function of kidney grafts from cardiac death donors in rat. Transplant Proc 46:1578-1584

Kalaz EB, Jale Çoban A, Aydın F, Doğan-Ekici I, Doğru-Abbasoğlu S, Öztezcan S, Uysal M (2014) Carnosine and taurine treatments decreased oxidative stress and tissue damage induced by D-galactose in rat liver. J Physiol Biochem 70:15-25

Kasahara N, Kikuchi T, Doi J, Teratani T, Fujimoto Y, Uemoto S, Yasuda Y, Kobayashi E (2013) Luminescence-based assay to screen preservation solutions for optimal ability to maintain viability of rat intestinal grafts. Transplant Proc 45:2486-2490

Kim SY, Park SC (2012) Physiological antioxidative network of the bilirubin system in aging and age-related diseases. Front Pharmacol 3:45

Kim SW, Wu G (2009) Regulatory role for amino acids in mammary gland growth and milk synthesis. Amino Acids 37:89-95

Larqué E, Sabater-Molina M, Zamora S (2007) Biological significance of dietary polyamines. Nutrition 23:87-95

Lee AC, Fenster BE, Ito H, Takeda K, Bae NS, Hirai T, Yu ZX, Ferrans VJ, Howard BH, Finkel T (1999) Ras proteins induce senescence by altering the intracellular levels of reactive oxygen species. J Biol Chem 274:7936-7940

Löser C (2000) Polyamines in human and animal milk. Br J Nutr 84:S55-S58

Maeda M, Kasahara N, Doi J, Iijima Y, Kikuchi T, Teratani T, Kobayashi E (2013) A luminance-based heart chip assay for assessing the efficacy of graft-preservation solutions in heart transplantation in rats. Heart Asia 5:7-14

Mattoo AK, Minocha SC, Minocha R, Handa AK (2010) Polyamines and cellular metabolism in plants: transgenic approaches reveal different responses to diamine putrescine versus higher polyamines spermidine and spermine. Amino Acids 38:405-413

Minois N, Carmona-Gutierrez D, Madeo F (2011) Polyamines in aging and disease. Aging (albany NY) 3:716-732

Negishi K, Teratani T, Iwasaki J, Kanazawa H, Kasahara N, Lefor A, Uemoto S, Fujimoto Y, Kobayashi E (2011) Luminescence technology in preservation and transplantation for rat islet. Islets 3:111-117

Nishimura K, Shiina R, Kashiwagi K, Iagarashi K (2006) Decrease in polyamines with aging and their ingestion from food and drink. J Biochem 139:81-90

Okita N, Kudo Y, Tanuma S (2007) Checkpoint kinase 1 is cleaved in a caspase-dependent pathway during genotoxic stress-induced apoptosis. Biol Pharm Bull 30:359-362

Okumura S, Teratani T, Fujimoto Y, Zhao X, Tsuruyama T, Masano Y, Kasahara N, Iida T, Yagi S, Uemoto S, Kaido T, Uemoto S (2016) Oral administration of polyamines ameliorates liver ischemia/reperfusion injury and promotes liver regenaration in rats. Liver Transpl 22:1231-1244

Osborne DL, Seidel ER (1990) Gastrointestinal luminal polyamines: cellular accumulation and enterohepatic circulation. Am J Physiol 258:G576-G584

Pegg AE (1988) Polyamine metabolism and its importance in neoplastic growth and a target for chemotherapy. Cancer Res 48:759-774

Rigueira JC, Rodrigues MI, Gloria MB (2011) Optimization of the analytical extraction of polyamines from milk. Talanta 86:195-199

Rodríguez MI, Escames G, López LC, López A, García JA, Ortiz F, Sánchez V, Romeu M, Darío A-C (2008) Improved mitochondrial function and increased life span after chronic melatonin treatment in senescent prone mice. Exp Gerontol 43:749-756

Romain N, Dandrifosse G, Jeusette F, Forget P (1992) Polyamine concentration in rat milk and food, human milk, and infant formulas. Pediatr Res 32:58-63 
Saeki K, Nose Y, Hirao N, Takasawa R, Tanuma S (2011) Amyloid precursor protein binding protein Fe65 is cleaved by caspases during DNA damage-induced apoptosis. Biol Pharm Bull 34:290-294

Sakata K, Kashiwagi K, Sharmin S, Ueda S, Irei Y, Murotani N, Igarashi K (2003) Increase in putrescine, amine oxidase, and acrolein in plasma of renal failure patients. Biochem Biophys Res Commun 305:143-149

Scalabrino G, Ferioli ME (1984) Polyamines in mammalian ageing: an oncological problem, too? A review. Mech Ageing Dev 26:149-164

Singh R, Kanwar SS, Sood PK, Nehru B (2011) Beneficial effects of folic acid on enhancement of memory and antioxidant status in aged rat brain. Cell Mol Neurobiol 31:83-91

Tavladoraki P, Cona A, Federico R, Tempera G, Viceconte N, Saccoccio S, Battaglia V, Toninello A, Agostinelli E (2011) Polyamine catabolism: target for antiproliferative therapies in animals and stress tolerance strategies in plants. Amino Acids 2011 (in press)
Teratani T, Kobayashi E (2011) In vivo Bioimaging rats for translational research in cell/tissue transplantation. Cell Medicine (in press)

Teratani T, Kobayashi E (2012) In vivo bioimaging rats for translational research in cell and tissue transplantation. Cell Med 3:3-11

von Deutsch AW, Mitchell CD, Williams CE, Dutt K, Silvestrov NA, Klement BJ, Abukhalaf IK, von Deutsch DA (2005) Polyamines protect against radiation-induced oxidative stress. Gravit Space Biol Bull 18:109-110

Publisher's Note Springer Nature remains neutral with regard to jurisdictional claims in published maps and institutional affiliations. 